\title{
Pre-divorce problems in 3-year-olds: a prospective study in boys and girls
}

\author{
Sylvana C. C. Robbers $\cdot$ Meike Bartels $\cdot$ \\ C. E. M. Toos van Beijsterveldt • Frank C. Verhulst • \\ Anja C. Huizink · Dorret I. Boomsma
}

Received: 3 July 2009/Accepted: 18 February 2010/Published online: 7 March 2010

(c) The Author(s) 2010. This article is published with open access at Springerlink.com

\begin{abstract}
Objective We examined to what extent internalizing and externalizing problems at age 3 preceded and predicted parental divorce, and if divorce and the time lapse since divorce were related to internalizing and externalizing problems at age 12 .

Methods Parental ratings of internalizing and externalizing problems were collected with the Child Behavior Checklist (CBCL) in a large sample $(N=6,426)$ of 3-yearold children. All these children were followed through the age of 12 years, at which parents completed the CBCL again, while teachers completed the Teacher's Report Form. Children whose parents divorced between age 3 and age 12 were compared with children whose families remained intact.
\end{abstract}

S. C. C. Robbers · F. C. Verhulst · A. C. Huizink

Department of Child and Adolescent Psychiatry,

Erasmus University Medical Center, Sophia, Rotterdam,

The Netherlands

S. C. C. Robbers - M. Bartels - C. E. M. T. van Beijsterveldt ·

D. I. Boomsma

Department of Biological Psychology,

VU University Amsterdam, Amsterdam,

The Netherlands

\section{A. C. Huizink}

Department of Education, Faculty of Behavioral and Social

Sciences, University of Amsterdam, Amsterdam,

The Netherlands

\section{Bartels ( $\square)$}

Department of Biological Psychology, Room 2B-47,

Vrije Universiteit, Van Der Boechorststraat 1,

1081 BT Amsterdam, The Netherlands

e-mail: m.bartels@psy.vu.nl
Results Girls whose parents divorced between ages 3 and 12 already showed more externalizing problems at age 3 than girls whose parents stayed married. Higher levels of externalizing problems in girls at age 3 predicted later parental divorce. Parental reports indicated that 12-yearolds with divorced parents showed more internalizing and externalizing problems than children with married parents. Levels of teacher-reported problems were not different between children with married versus divorced parents. However, children whose parents divorced between ages 3 and 12 showed more teacher-rated internalizing problems at age 12 when the divorce was more recent than when the divorce was less recent. Parental ratings of both internalizing and externalizing problems at age 12 were not associated with the time lapse since divorce.

Conclusion Externalizing problems in girls precede and predict later parental divorce. Post-divorce problems in children vary by raters, and may depend on the time lapse since divorce.

Keywords Parental divorce - Pre-divorce problems . Internalizing and externalizing problems

\section{Introduction}

Each year 70,000 children in the Netherlands experience parental divorce [47]. This is $1.5 \%$ of the total number of Dutch children under the age of 21. An increase in divorce rates from $24 \%$ in 1980 to $34 \%$ in 2007 [18] has been observed. There is a general belief that parental divorce has negative effects on the well being of their offspring. Parental divorce is associated with children's externalizing problems, such as aggression and rule-breaking behavior, and with internalizing problems, such as anxiety and 
depression [6, 29]. On an average, children with divorced parents are emotionally, socially and academically less well adjusted than children with married parents [9, 33]. However, most studies assessed children's problems using only parents as a source of information. It is known that different informants, such as parents, teachers, or children themselves may differ in their reports of problems in the same child [4]. Although different, these reports reflect information that may be valid in its own way. Different informants may differ in the way they perceive problems, see children in different contexts, or interact with the child in different ways [10]. Because conclusions based on the multiple informants may give a more complete picture, we chose to use information of both parents and teachers on children's problems in the present study.

The etiology behind the association between parental divorce and children's problems is still unclear. Crosssectional studies that compared children of married versus divorced parents can not provide insight into the direction of the relationship between the experience of parental divorce and children's problems. Prospective studies that begin before the children's parents divorce are sparse, but show that some of the differences between children who experienced parental divorce and those who did not were already present before the divorce occurred. For instance, the behavior of 3-, 4- and 7-year-old boys was more problematic as early as 11 years prior to parental divorce than that of boys who did not experience parental divorce [14]. Because the effect was not found for girls, the authors concluded that pre-divorce stress may affect girls and boys differently. Boys and girls aged 4-11 whose parents later divorced within 4 years after initial assessment showed higher levels of anxiety, depression and antisocial behavior than those children whose parents remained married [48]. Problems in parent-child relationships were found 812 years before divorce [8]. Another study showed that the apparent effect of divorce on behavioral problems in 11-year-old children appeared to be sharply reduced when pre-existing problems were taken into consideration [22]. Finally, parents of youths diagnosed with ADHD in childhood were more likely to divorce and had a shorter latency to divorce when compared with parents of children without ADHD [53]. Taken together, behavioral problems may already be present in children long before the divorce actually occurs. These findings suggest that it is not the divorce per se that causes problems in children, and they may indicate characteristics of the children or their parents that influenced the parents' marriages and the children's lives [21].

Previous studies on pre- and post-divorce child problems do not sufficiently address both internalizing and externalizing problems and problems as reported by multiple informants, in particular teachers. In addition, a methodological problem in many previous studies is the lack of availability of children's age at the time of the divorce [5, 36]. Lansford et al. [37] addressed these issues, but they measured child problems ranging only from 1 year prior to 3 years after divorce. The present study compared internalizing and externalizing problems in a large sample of 3-year-old children $(N=6,426)$, who were followed through the age of 12 years. Children whose parents divorced or separated between the two time points were at both ages compared to children whose families stayed intact. Maternal, paternal and teacher reports were used to obtain information about children's behavioral problems. Because we had a large sample of children, we were able to investigate the associations between parental divorce and children's behavior problems separately for boys and girls. We expected that at the age of 12 years, boys and girls with divorced parents would show higher levels of internalizing and externalizing problems than boys and girls with married parents. More importantly, we expected that both boys and girls who had experienced parental divorce by the age of 12 would already show higher levels of problems at age 3 than those children whose parents remained married. We examined to what extent child problems at age 3 predicted parental divorce, and if child problems at age 12 were related to the time lapse since the divorce. It is sometimes assumed that children have more short-term adjustment difficulties immediately after their parents' divorce, and that these difficulties may lessen in severity following an adjustment period [20]. Therefore, we hypothesized that children have more problems at age 12 when they experienced the divorce more recently as opposed to less recently. Furthermore, we hypothesized that higher levels of internalizing and externalizing problems at age 3 would predict parental divorce between the ages of 3 and 12 years. Finally, the prevalence of internalizing problems shows no gender differences at ages 3 and 12, whereas externalizing problems are more prevalent in boys versus girls at both ages $[11,50]$. In the current study, we expect to find similar sex patterns.

\section{Methods}

Sample and procedure

Data were used from a longitudinal twin-family study that examines causes of individual differences in health, growth, and the development of behavioral and emotional problems. All participating families are volunteer members of the Netherlands Twin Registry, established by the Department of Biological Psychology at the VU University in Amsterdam [13, 15]. The study protocol was approved by the ethics committee of the VUMC (VU University 
medical centre), Amsterdam. For the present study, data from twins born between 1986 and 1993 were analyzed. Parents of twins received surveys by mail within 3 months of the twins' 3rd, 7th, 10th and 12th birthdays; 2-3 months after these mailings, reminders were sent to the nonresponders. Parents were invited to participate at each wave of data collection, regardless of their previous participation. Furthermore, surveys were sent to teachers after written permission was given by the parents. The absolute parental response rate at each measurement was $62 \%$. The teacher response rate was $74 \%$. Data were available for 6,426 children. There were 3,139 boys $(49 \%)$ and 3,287 girls $(51 \%)$.

\section{Measures}

\section{Internalizing and externalizing problems}

When the children were 3 years old, mother and father ratings were collected with the Child Behavior Checklist (CBCL/2-3) [1]. The CBCL/2-3 was developed for parents to score the behavior of their 2- and 3-year-old children. It consists of 100 items that are scored on a 3-point scale that is based on the occurrence of the behavior during the 2 months prior to the survey: 0 if the problem item was not true, 1 if the item was somewhat or sometimes true and 2 if it was very true or often true. The internalizing scale comprised the anxious and withdrawn/depressed syndromes, and consisted of 19 items; the externalizing scale comprised the oppositional, aggressive, and overactive syndromes, and consisted of 31 items [34]. The validity and reliability of these CBCL scales have been supported by a wide variety of studies [35]. For a total of 6,192 children mother ratings of internalizing problems were available. Mother ratings of externalizing problems were available for 6,190 children. Owing to financial restrictions, father ratings were not collected in all birth cohorts, and problems were available for 3,657 children.

Mother and father ratings of internalizing and externalizing problems at age 12 were collected with the CBCL/ 4-18 [2, 51] that consists of 120 items with the same three response categories as the $\mathrm{CBCL} / 2-3$. Parents were instructed to rate the child's behavior over the preceding 6 months. The good reliability and validity of the CBCL/ 4-18 were confirmed for the Dutch version of the measure: Cronbach's alpha was 0.84 (boys) and 0.85 (girls) for the internalizing scale and 0.86 (boys) and 0.85 (girls) for the externalizing scale [51]. The internalizing scale consists of the anxious/depressed, somatic complaints, and withdrawn subscales, and consists of 31 items. The externalizing scale consists of the aggressive behavior and rule-breaking behavior subscales, and consists of 30 items. Mother ratings of internalizing and externalizing problems at age 12 were available for 6,245 and 6,301 children, respectively. Father ratings of internalizing problems at age 12 were available for 4,839 children, and father ratings of externalizing problems were available for 4,850 children.

Teacher ratings were collected at age 12 with the Teacher Report Form (TRF) [3,52] that consists of 120 items with the same response categories as the CBCL/2-3 and CBCL/4-18. Teachers were instructed to rate the child's behavior over the preceding 2 months. The good reliability and validity of the TRF were confirmed for the Dutch version: Cronbach's alpha was 0.86 (boys) and 0.89 (girls) for the internalizing scale and 0.95 (boys) and 0.94 (girls) for the externalizing scale [52]. The internalizing and externalizing scales consist of the same subscales as in the CBCL/4-18; however, the number of items is different: the internalizing scale consists of 36 items, and the externalizing scale consists of 34 items. Teacher ratings of internalizing and externalizing problems were available for 2,841 and 2,885 children, respectively. Collection of TRF ratings started halfway 1986 and TRF data were available until 1993.

\section{Socioeconomic status}

Socioeconomic status at age 3 was included in this study as a covariate. For about two-third of the twin sample, SES was obtained from a full description of the occupation of the parents, and SES was subsequently coded according to the standard classification of occupations [19]. For the remaining twins, SES was obtained by the EPG-classification scheme [26], combined with information on parental education. For all twins, the level of occupation was classified into three SES levels $(1=$ low; $2=$ middle; $3=$ high). For 122 twins (1.9\% of the sample) SES status at age 3 was unknown.

\section{Family status}

Family status for birth cohorts 1986-1991 was assessed in surveys mailed when the children were aged 12. Family status for birth cohorts 1992 and 1993 was assessed when the children were aged 10 and 12. Marital status of the parents was defined as 'married and/or living together'. There were two items in the surveys to assess the family situation. The first item was Which of the following statements corresponds best with the twin's current family situation? Possible answers were (1) the biological mother and the biological father are married or are living together; (2) the biological mother and the biological father have been divorced since ... (3) the biological mother has been deceased since... (4) the biological father has been deceased since... (5) different family situation, namely... The parent was able to fill in the appropriate dates on the dots, or indicate any other possible family situation. The 
second item was Which of the following statements corresponds best with the twin's current living situation? Possible answers were (1) the twin lives with both biological parents; (2) the twin lives with the biological mother only; (3) the twin lives with the biological father only; (4) the twin lives with the biological mother and her partner (not the biological father); (5) the twin lives with the biological father and his partner (not the biological mother); (6) different living situation, namely... The parent was able to indicate any other possible family living situation on the dots. In order to accurately determine family status at the child's ages of 3 and 12 years, the information from both items was combined.

When parents indicated to be divorced, we needed to determine if they were already divorced when they completed the CBCL/2-3. Therefore, the date of divorce was compared to the date the parents completed the CBCL/2-3. If parents did not indicate the date they completed the $\mathrm{CBCL} / 2-3$, we checked whether the divorce took place before or after age 3 years of their children. If their children were younger than 4 years at the time of the divorce, we considered the parents to be divorced when they completed the CBCL/2-3.

\section{Dataset}

The original dataset consisted of 8,664 twin pairs. Twin pairs were excluded from the current study if there was a maternal or paternal death ( $N=95$ twin pairs), if information on divorce could not be ascertained ( $N=261$ twin pairs), if the twin pairs did not live with their biological parents $(N=18$ twin pairs), or if parents did not indicate the date of their divorce ( $N=17$ twin pairs). For about half of the twin pairs in the dataset $(N=4,424$ twin pairs) no information was available at age 12 , which can be explained by the presence of children from birth cohorts later than 1993 who had not yet reached the age of 12 years. The remaining dataset with 3,849 twin pairs represented a total of 7,698 children. From this sample, children were further excluded if no behavioral information was available at age $3(N=1,108$ children $)$ and if parents were already divorced by the time the CBCL/2-3 was completed ( $N=164$ children). The final sample consisted of 6,426 children, who were divided into two groups: (1) 5,946 (92.5\%) children (2,887 boys and 3,059 girls) whose parents were still married when they reached the age of 12 years; (2) 480 ( $7.5 \%$ ) children ( 252 boys and 228 girls) whose parents divorced when they were between 3 and 12 years old.

\section{Strategy of analysis}

Mean problem scores were estimated in Mplus Version 5 [42] using maximum likelihood with robust standard errors
(MLR). MLR adjusts for non-independence and non-normality of the scores [42]. For all mean comparisons, we used MLR $\chi^{2}$ difference testing, in which the MLR $\chi^{2}$ is equal to the obtained $\chi^{2}$ divided by the scaling correction factor [41]. We allowed for the analysis of cases with missing values because (1) not all children had both internalizing and externalizing scores at each age; (2) not for all children problem scores from all three informants were available; (3) information on socioeconomic status was not available for all children. First, we tested for group differences in sex and in socioeconomic status, and for sex differences in the internalizing and externalizing problem scores at ages 3 and 12. Then, we tested if the mean problem scores differed between the two groups of offspring of divorced and non-divorced parents at both age 3 and 12 years.

To examine if internalizing and externalizing problems at age 3 predicted parental divorce, we carried out continuous-time survival analyses (Cox regressions) in Mplus while again controlling for the dependency between the scores of twins and for socioeconomic status. The estimator used in these analyses was again MLR. A non-parametric baseline hazard function was applied. Survival time was considered 'the number of months from completion of the CBCL/2-3 to the actual divorce'. We created this variable by means of the child's age in months at the time of the divorce. We tested for interaction effects of sex with the predictors, i.e. the internalizing and externalizing problem scores at age 3 . The results are presented as the log odds of the incremental probability of divorce for a one unit change in the predictors.

To examine the association between the time lapse since divorce and internalizing and externalizing problems at age 12 , regression analyses were conducted with the number of months from completion of the CBCL/2-3 to the actual divorce as the predictor variable (divorce interval). For these analyses, children were selected whose parents divorced between ages 3 and 12. Data from boys and girls were analyzed simultaneously with sex and SES added as additional predictors in the model, and we tested for interaction effects of divorce interval with sex. We again used MLR to control for the dependency between twins. For all analyses, a statistical significance at the level of $P<0.05$ was chosen.

\section{Results}

For parent-reported internalizing problems the scores ranged from 0 to 28 at age 3 , and from 0 to 49 at age 12 . The scores for parent-reported externalizing problems at age 3 ranged from 0 to 55; at age 12 these scores ranged from 0 to 50 . Teacher-reported internalizing problems at age 12 
ranged from 0 to 37 , and teacher-reported externalizing problems at age 12 ranged from 0 to 52 . The age 3 problem scores correlated moderately with the parent-reported problem scores at age $12(r=0.26-0.44)$. The TRF scores correlated moderately with the CBCL ratings at age 12 $(r=0.24-0.38)$. Sex was equally distributed between the two groups of children $\left(\chi^{2}=2.768, P=0.10\right)$. No sex differences were found for internalizing problems at both ages. For externalizing problems, boys had higher problem scores than girls at both ages and according to all informants $(P<0.001)$.

Tables 1 (mother ratings), 2 (father ratings) and 3 (teacher ratings) display the means and standard errors of the internalizing and externalizing problem scores at age 3 and age 12 per group. All means are within the normal range [35], and were corrected for the dependency between twins and for socioeconomic status at age 3 .

The mean problem scores of children with married parents were compared with those of children whose parents divorced between the ages of 3 and 12. Divorced parents reported more internalizing and externalizing problems in their 12-year-old children than married parents (all $P<0.05$ ). However, according to the teachers, there was no significant difference in the level of internalizing and externalizing problems between children of married versus divorced parents. At age 3, girls whose parents later divorced showed more externalizing problems than girls whose parents stayed married $(P<0.001$ for both mother and father ratings). Boys whose parents divorced after age 3 did not show more externalizing problems at age 3 than boys whose parents stayed married. Children whose parents divorced after age 3 did not show more internalizing problems at age 3 than children whose parents stayed married. Mother and father ratings showed the same pattern of results.
Continuous-time survival analyses were carried out to examine if the levels of problems at age 3 predicted divorce. The survival time, which was the number of months in which parental divorce took place, ranged from 0 to 102 months, indicating that parental divorce took place at a maximum child age of 12.5 years. The mean number of months between age 3 and parental divorce was $M=49.78 \quad(\mathrm{SD}=27.64)$, which corresponds with the child's age of 8 years. A total of $21 \%$ of the 'divorcing' children experienced parental divorce between the ages of 4 and 6 , and $75 \%$ of these children had experienced parental divorce by the age of 10 . Sex of the child did not significantly predict parental divorce $(P=0.15)$, when entered in the model as a sole predictor. All sex interactions significantly predicted divorce $(P<0.05)$, except for the interaction of sex with mother ratings of internalizing problems $(P=0.68)$. Mother and father ratings of externalizing problems and father ratings of internalizing problems were, therefore, further analyzed per sex. The survival analyses indicated that the level of girls' externalizing problems significantly predicted parental divorce (log odds mother ratings $=0.025, \mathrm{SE}=0.008, P<0.01$; $\log$ odds father ratings $=0.039, \mathrm{SE}=0.010, P<0.001$ ). Internalizing problems and boys' externalizing problems did not significantly predict parental divorce.

Next, the association between divorce interval and child problems at age 12 was investigated. There was a main effect of divorce interval on teacher-rated internalizing problems $(\beta=0.03, P=0.04)$, implying that children who had experienced parental divorce more recently had more internalizing problems than children who had experienced the divorce less recently. The interactions with sex were only significant for mother-rated externalizing problems $(\beta=0.04, P=0.04)$ : for boys there was a trend to show fewer externalizing problems at age 12 if the divorce
Table 1 Means and standard errors of internalizing and externalizing problems at age 3 and 12 of married and divorced children as rated by the mother

\begin{tabular}{|c|c|c|c|c|}
\hline & $\begin{array}{l}\text { Married } \\
\text { until age } 12\end{array}$ & $\begin{array}{l}\text { Divorced between } \\
\text { age } 3 \text { and } 12\end{array}$ & $\begin{array}{l}\text { MLR } \chi^{2} \\
\text { difference }\end{array}$ & $P$ value \\
\hline \multicolumn{5}{|c|}{ Age 3 internalizing } \\
\hline Boys & $4.54(0.08)$ & $4.67(0.24)$ & 0.124 & 0.72 \\
\hline Girls & $4.45(0.09)$ & $4.85(0.34)$ & 1.639 & 0.20 \\
\hline \multicolumn{5}{|c|}{ Age 3 externalizing } \\
\hline Boys & $16.49(0.23)$ & $17.08(0.74)$ & 0.426 & 0.51 \\
\hline Girls & $14.52(0.21)$ & $17.04(0.82)$ & 11.438 & $<0.001$ \\
\hline \multicolumn{5}{|c|}{ Age 12 internalizing } \\
\hline Boys & $4.18(0.11)$ & $5.92(0.47)$ & 37.956 & $<0.001$ \\
\hline Girls & $4.32(0.10)$ & $6.27(0.50)$ & 62.256 & $<0.001$ \\
\hline \multicolumn{5}{|c|}{ Age 12 externalizing } \\
\hline Boys & $6.98(0.16)$ & $8.36(0.53)$ & 10.066 & $<0.01$ \\
\hline Girls & $4.71(0.11)$ & $7.06(0.45)$ & 125.024 & $<0.001$ \\
\hline
\end{tabular}


Table 2 Means and standard errors of internalizing and externalizing problems at age 3 and 12 of married and divorced children as rated by the father

\begin{tabular}{|c|c|c|c|c|}
\hline & $\begin{array}{l}\text { Married } \\
\text { until age } 12\end{array}$ & $\begin{array}{l}\text { Divorced between } \\
\text { age } 3 \text { and } 12\end{array}$ & $\begin{array}{l}\text { MLR } \chi^{2} \\
\text { difference }\end{array}$ & $P$ value \\
\hline \multicolumn{5}{|c|}{ Age 3 internalizing } \\
\hline Boys & $4.37(0.10)$ & $4.28(0.28)$ & 0.058 & 0.81 \\
\hline Girls & $4.27(0.10)$ & $4.88(0.41)$ & 3.164 & 0.08 \\
\hline \multicolumn{5}{|c|}{ Age 3 externalizing } \\
\hline Boys & $15.46(0.25)$ & $16.07(0.76)$ & 0.441 & 0.51 \\
\hline Girls & $13.82(0.23)$ & $16.38(0.92)$ & 11.575 & $<0.001$ \\
\hline \multicolumn{5}{|c|}{ Age 12 internalizing } \\
\hline Boys & $3.45(0.11)$ & $5.46(0.57)$ & 23.411 & $<0.001$ \\
\hline Girls & $3.25(0.09)$ & $5.18(0.54)$ & 102.630 & $<0.001$ \\
\hline \multicolumn{5}{|c|}{ Age 12 externalizing } \\
\hline Boys & $6.21(0.16)$ & $7.72(0.77)$ & 4.150 & 0.04 \\
\hline Girls & $4.02(0.11)$ & $5.90(0.54)$ & 77.567 & $<0.001$ \\
\hline
\end{tabular}

Table 3 Means and standard errors of internalizing and externalizing problems at age 12 of married and divorced children as rated by the teacher

\begin{tabular}{|c|c|c|c|c|}
\hline & $\begin{array}{l}\text { Married } \\
\text { until age } 12\end{array}$ & $\begin{array}{l}\text { Divorced between } \\
\text { age } 3 \text { and } 12\end{array}$ & $\begin{array}{l}\text { MLR } \chi^{2} \\
\text { difference }\end{array}$ & $P$ value \\
\hline \multicolumn{5}{|c|}{ Age 12 internalizing } \\
\hline Boys & $4.58(0.18)$ & $5.21(0.60)$ & 1.682 & 0.19 \\
\hline Girls & $4.31(0.16)$ & $4.98(0.56)$ & 0.303 & 0.58 \\
\hline \multicolumn{5}{|c|}{ Age 12 externalizing } \\
\hline Boys & $6.16(0.27)$ & $6.68(0.96)$ & 1.611 & 0.20 \\
\hline Girls & $2.69(0.17)$ & $2.74(0.66)$ & 0.005 & 0.94 \\
\hline
\end{tabular}

was more recent $(\beta=-0.04, P=0.06)$, while for girls this effect was not significant.

\section{Discussion}

In numerous studies over the past decades, children of divorced parents have been reported to show more behavioral problems than children of married parents [9, 29]. Our study yielded similar results: when boys and girls from married and divorced families were compared at the age of 12 years, we found that divorced parents reported more problems in their children than married parents. However, teacher ratings of internalizing and externalizing problems did not reveal any significant differences between children from married and divorced parents. This finding is in line with an earlier study in Chinese children that found that teachers reported less differences between children of married and divorced parents than their parents did [38]. This inconsistency between parental and teacher reports may indicate that children differ in the context in which they manifest their behavioral problems, divorced parents may over-report children's problems or they may be more sensitive to them, or teachers and parents differ in their knowledge of normative child behaviors. When compared with teachers, mothers have less knowledge of normative child behaviors on which to base their judgments, which may result in more immoderate assessments of children's behaviors [17, 40]. Over-reporting could be due to parental characteristics, such as anxiety or depression [28], to parents' concern about their children's mental health, or to their own distress associated with the divorce [38]. Our results seem in contrast with the findings that divorced parents may tend to underestimate their children's problems [9]. As the long-term impact of divorce could be different between the sexes [45], it would be interesting to extend our study with adult behavioral and emotional problems of these children.

We found evidence for pre-divorce externalizing problems in 3-year-old girls. This finding suggests that at least part of the higher levels of parent-reported externalizing problems in 12-year-old girls is not likely to be caused by the parental divorce, but by conditions that existed well before the divorce occurred. Furthermore, not only were the mean levels of problems of girls whose parents divorced between the ages of 3 and 12 higher than those of girls whose parents stayed married, but girls' externalizing problems also significantly predicted later parental divorce. Our finding is in line with earlier research that showed that marital conflict predicted changes in children's behavior, but that at the same 
time children's behavior also predicted an increase in marital conflict [30]. Unfortunately, our results do not provide any insight into the reasons why girls and not boys showed predivorce externalizing problems and why only girls' behavior problems predicted parental divorce. It could be the case that increased levels of externalizing problems are more notable in girls than in boys, and may evoke more familial stress. In contrast with our hypotheses, we did not find evidence for pre-divorce internalizing problems. The higher levels of internalizing problems in children of divorced parents at age 12 appear to be due, at least in part, to the parental separation.

An often-mentioned and investigated explanation for predivorce problems in children is the presence and the level of marital conflict and familial stress preceding the actual marital break-up [16, 33]. An overwhelming number of studies have demonstrated associations between marital conflict and childhood problems [23]. Parental conflict appears to be a more important predictor of child psychopathology than the divorce itself [33]. Although the maximum time interval to divorce in our study was large (9 years), it is possible that part of the observed pre-divorce externalizing problems in girls is due to marital conflict. Another explanation for pre-divorce problems may be found in genetics. Parental divorce increases the likelihood that offspring will divorce [7] and it has been suggested that divorce risk is heritable [39]. The heritability of divorce risk could be due to genetic transmission of personality traits that make individuals liable to divorce. A study from the Minnesota Twin Registry showed for example that for women and men, respectively, 30 and $42 \%$ of the association between personality and divorce was accounted for by genetic factors [31]. An association between personality and divorce has been found in many studies. For example, extraversion and neuroticism appear to be positively related to risk of divorce [27, 32]. Like divorce risk, internalizing and externalizing problems are influenced by genetic factors. These explain about $50 \%$ of the variance of internalizing and externalizing problems at ages 3 and 7, indicating an inborn vulnerability to child psychopathology [12, 50]. Because both divorce risk and problem behaviors have a strong genetic basis, a likely hypothesis is that the association between divorce and internalizing or externalizing problems does not exist because divorce causes these problems or vice versa, but because genetically influenced correlated factors account for the association. A number of studies addressed this possibility [24, 25, 43, 44] and found evidence for genetic factors influencing the associations between parental divorce and offspring problems. Our findings with regard to girls' externalizing problems endorse the results of these behavioral genetic studies. We suggest that a shared genetic tendency in a family to exhibit increased levels of externalizing behaviors, could contribute to parents' marital distress and divorce, and to children's behavioral problems.
Children showed more teacher-rated internalizing problems at age 12 when the divorce was more recent as opposed to less recent. However, this association was not observed for parent-rated problems at age 12. Therefore, the belief that children have more short-term adjustment difficulties immediately after their parents' divorce, and that these difficulties may lessen in severity following an initial adjustment period, may have limited validity. Alternatively, shortly after divorce parents may be less sensitive to the behavioral and emotional problems of their offspring. To the best of our knowledge, there are no other studies that have used an indicator of children's ages at the time of their parents' divorce, and that have accounted for the time lapse to the divorce in their analyses. Further research is therefore needed to explore these effects.

Powerful and unique aspects of this study are the large number of participating families, the accurate measurement of the time lapse to the divorce, the large time span between the two behavioral assessments, and the use of multiple informants. Beside these strong aspects, some limitations of the current study need to be mentioned. First, the use of twins for studies of normal behavioral development is still a topic of debate, because the behavioral development of twins and singletons could be different. However, a recent study confirmed the generalizability of results from twin studies to singletons with regard to externalizing problems in middle and late childhood. Twinsingleton differences in internalizing problems were only found in early adolescence [46]. In addition, the general level of problem behaviors in twins at age 3 is broadly comparable to that in singletons [49]. Second, we can not determine whether the observed frequency of divorce in our twin sample is representative for the general population. However, when considering that in general about onethird of all marriages end in divorce, the divorce frequency observed in our sample does not seem to be outside the range of normal expectation. Third, we derived divorce status at age 3 from information collected at a later time (i.e. at age 7, 10 and 12). Although unlikely, this may have caused unreliability of divorce status at age 3 in some cases due to recall bias. Fourth, the classification system to determine socioeconomic status was not the same for all children. However, we believe we adequately combined the two classification systems, to retrieve a representative measure of socioeconomic status. Finally, it would be informative to include other covariates, such as the level of marital conflict at several time points.

\section{Conclusion}

Externalizing problems in girls precede and predict later parental divorce. Post-divorce problems in children vary by 
raters, and may depend on the time lapse since the divorce. Future research should prospectively measure both marital conflict, timing of divorce, and pre- and post-divorce child problems using multiple raters to increase our understanding of the etiology of pre-divorce problems in children. In addition, it is of interest to extend our study with adult behavioral and emotional problems in offspring from divorced families.

Acknowledgments Data collection was funded by Grants "Genetics of externalizing disorders in children" (NWO 904-57-94), "Spinozapremie" (NWO/SPI 56-464-14192), "Twin-family database for behavior genetics and genomics studies" (NWO 480-04-004), "Twin research focusing on behavior and depression" (NWO 400-05-717), "Developmental Study of Attention Problems in Young Twins" (NIMH, RO1 MH58799-03), and "Bridge Award" (NIMH R56). Meike Bartels is financially supported by a NWO (Veni; Grant number: 451-04-034). Sylvana Robbers is supported by the Sophia Children's Hospital Foundation, project number 483.

Open Access This article is distributed under the terms of the Creative Commons Attribution Noncommercial License which permits any noncommercial use, distribution, and reproduction in any medium, provided the original author(s) and source are credited.

\section{References}

1. Achenbach TM (1992) Manual for the child behavior checklist/ 2-3 and 1992 profile. Department of Psychiatry, University of Vermont, Burlington, VT

2. Achenbach TM (1991) Manual for the child behavior checklist/ 4-18 and 1991 profiles. Department of Psychiatry, University of Vermont, Burlington, VT

3. Achenbach TM (1991) Manual for the Teacher's Report Form and 1991 profiles. Department of Psychiatry, University of Vermont, Burlington, VT

4. Achenbach TM, McConaughy SH, Howell CT (1987) Child/ adolescent behavioral and emotional problems: implications of cross-informant correlations for situational specificity. Psychol Bull 101:213-232

5. Amato PR (2001) Children of divorce in the 1990s: an update of the Amato and Keith (1991) meta-analysis. J Fam Psychol $15: 355-370$

6. Amato PR (2000) The consequences of divorce for adults and children. J Marriage Fam 62:1269-1287

7. Amato PR (1996) Explaining the intergenerational transmission of divorce. J Marriage Fam 58:628-640

8. Amato PR, Booth A (1996) A prospective study of divorce and parent-child relationships. J Marriage Fam 58:356-365

9. Amato PR, Keith B (1991) Parental divorce and the well-being of children: a meta-analysis. Psychol Bull 110:26-46

10. Bartels M, Boomsma DI, Van Beijsterveldt CEM, Hudziak JJ, Van den Oord EJ (2007) Twins and the study of rater (dis)agreement. Psychol Methods 12:451-466

11. Bartels M, Hudziak JJ, Boomsma DI, Rietveld MJH, Van Beijsterveldt TCEM, Van den Oord EJCG (2003) A study of parent ratings of internalizing and externalizing problem behavior in 12-year-old twins. J Am Acad Child Adolesc Psychiatry 42:1351-1359

12. Bartels M, Hudziak JJ, Van den Oord EJCG, Rietveld MJH, Van Beijsterveldt TCEM, Boomsma DI (2004) Genetic and environmental mechanisms underlying stability and change in problem behaviors at ages 3, 7, 10 and 12. Dev Psychol 40:852867

13. Bartels M, Van Beijsterveldt CEM, Derks EM, Stroet TM, Polderman TJC, Hudziak JJ, Boomsma DI (2007) Young Netherlands twin register (Y-NTR): a longitudinal multiple informant study of problem behavior. Twin Res Hum Genet 10:3-11

14. Block JH, Block J, Gjerde PF (1986) The personality of children prior to divorce: a prospective study. Child Dev 57:827-840

15. Boomsma DI, De Geus EJ, Vink JM, Stubbe JH, Distel MA, Hottenga JJ, Posthuma D, Van Beijsterveldt TCEM, Hudziak JJ, Bartels M, Willemsen GAHM (2006) Netherlands twin register: from twins to twin families. Twin Res Hum Genet 9:849-857

16. Bryner CL Jr (2001) Children of divorce. J Am Board Fam Pract 14:201-210

17. Campbell SB (2002) Behavior problems in preschool children: clinical and developmental issues. Guilford Press, New York

18. CBS (2008) Huwelijksontbindingen door echtscheiding en door overlijden. In: Centraal Bureau voor de Statistiek

19. CBS (2001) Standard classification of occupations. In: Central Bureau of Statistics, Heerlen/Voorburg

20. Chase-Lansdale PL, Hetherington EM (1990) The impact of divorce on life-span development: short and long term effects. In: Baltes PB, Featherman DL, Lerner RM (eds) Life-span development and behavior. Erlbaum, Hillsdale, pp 105-150

21. Cherlin AJ, Chase-Lansdale PL, McRae C (1998) Effects of parental divorce on mental health throughout the life course. Am Sociol Rev 63:239-249

22. Cherlin AJ, Furstenberg FF Jr, Chase-Lansdale L, Kiernan KE, Robins PK, Morrison DR, Teitler JO (1991) Longitudinal studies of effects of divorce on children in Great Britain and the United States. Science (New York) 252:1386-1389

23. Cummings ME, Davies PT (2002) Effects of marital conflict on children: recent advances and emerging themes in process-oriented research. J Child Psychol Psychiatry 43:31-63

24. D'Onofrio BM, Turkheimer E, Emery RE, Maes HH, Silberg J, Eaves LJ (2007) A children of twins study of parental divorce and offspring psychopathology. J Child Psychol Psychiatry 48:667675

25. D'Onofrio BM, Turkheimer E, Emery RE, Slutske WS, Heath AC, Madden PA, Martin NG (2006) A genetically informed study of the processes underlying the association between parental marital instability and offspring adjustment. Dev Psychol 42:486-499

26. Erikson R, Goldthorpe JH, Portocarero L (1979) Intergenerational class mobility in three Western European societies: England, France and Sweden. Br J Sociol 30:415-441

27. Eysenck HJ (1980) Personality, marital satisfaction, and divorce. Psychol Rep 47:1235-1238

28. Fergusson DM, Lynskey MT, Horwood LJ (1993) The effect of maternal depression on maternal ratings of child behavior. $\mathrm{J}$ Abnorm Child Psychol 21:245-269

29. Hetherington EM, Stanley-Hagan M (1999) The adjustment of children with divorced parents: a risk and resiliency perspective. J Child Psychol Psychiatry 40:129-140

30. Jenkins J, Simpson A, Dunn J, Rasbash J, O’Connor TG (2005) Mutual influence of marital conflict and children's behavior problems: shared and nonshared family risks. Child Dev 76:24-39

31. Jockin V, McGue M, Lykken DT (1996) Personality and divorce: a genetic analysis. J Pers Soc Psychol 71:288-299

32. Kelly EL, Conley JJ (1987) Personality and compatibility: a prospective analysis of marital stability and marital satisfaction. J Pers Soc Psychol 52:27-40

33. Kelly JB (2000) Children's adjustment in conflicted marriage and divorce: a decade review of research. J Am Acad Child Adolesc Psychiatry 39:963-973 
34. Koot HM, Van den Oord EJ, Verhulst FC, Boomsma DI (1997) Behavioral and emotional problems in young preschoolers: crosscultural testing of the validity of the Child Behavior Checklist/ 2-3. J Abnorm Child Psychol 25:183-196

35. Koot HM, Verhulst FC (1991) Prevalence of problem behavior in Dutch children aged 2-3. Acta Psychol Scand 83:1-37

36. Lansford JE (2009) Parental divorce and children's adjustment. Perspect Psychol Sci 4:140-152

37. Lansford JE, Malone PS, Castellino DR, Dodge KA, Pettit GS, Bates JE (2006) Trajectories of internalizing, externalizing, and grades for children who have and have not experienced their parents' divorce or separation. J Fam Psychol 20:292-301

38. Liu X, Guo C, Okawa M, Zhai J, Li Y, Uchiyama M, Neiderhiser JM, Kurita H (2000) Behavioral and emotional problems in Chinese children of divorced parents. J Am Acad Child Adolesc Psychiatry 39:896-903

39. McGue M, Lykken DT (1992) Genetic Influence on risk of divorce. Psychol Sci 3:368-373

40. Miner JL, Clarke-Stewart KA (2008) Trajectories of externalizing behavior from age 2 to age 9: relations with gender, temperament, ethnicity, parenting, and rater. Dev Psychol 44:771-786

41. Muthén BO, Muthén LK (2005) Chi-square difference testing using the Satorra-Bentler scaled chi-square. Available via http://www.statmodel.com/chidiff/shtml

42. Muthén LK, Muthén BO (1998-2007) Mplus User’s Guide, 5 edn. Muthén \& Muthén, Los Angeles

43. O'Connor TG, Caspi A, DeFries JC, Plomin R (2000) Are associations between parental divorce and children's adjustment genetically mediated? An adoption study. Dev Psychol 36:429437

44. O'Connor TG, Caspi A, DeFries JC, Plomin R (2003) Genotypeenvironment interaction in children's adjustment to parental separation. J Child Psychol Psychiatry 44:849-856
45. Pirkola S, Isometsa E, Aro H, Kestila L, Hamalainen J, Veijola J, Kiviruusu O, Lonnqvist J (2005) Childhood adversities as risk factors for adult mental disorders. Soc Psychiatry Psychiatr Epidemiol 40:769-777

46. Robbers SCC, Bartels M, Van Oort FVA, Van Beijsterveldt CEM, Van der Ende J, Verhulst FC, Boomsma DI, Huizink AC (in press) A twin-singleton comparison of developmental trajectories of externalizing and internalizing problems in 6- to 12-year-old children. Twin Res Hum Genet

47. Spruijt E (2007) Scheidingskinderen. Uitgeverij SPW, Amsterdam

48. Strohschein L (2005) Parental divorce and child mental health trajectories. J Marriage Fam 67:1286-1300

49. Van den Oord EJ, Koot HM, Boomsma DI, Verhulst FC, Orlebeke JF (1995) A twin-singleton comparison of problem behaviour in 2-3-year-olds. J Child Psychol Psychiatry 36:449458

50. Van der Valk JC, Van den Oord EJ, Verhulst FC, Boomsma D (2001) Using parental ratings to study the etiology of 3-year-old twins' problem behaviors: different views or rater bias? J Child Psychol Psychiatry 42:921-931

51. Verhulst FC, Van der Ende J, Koot HM (1996) Handleiding voor de CBCL/4-18 [Dutch manual for the CBCL/4-18]. Academic Medical Center Rotterdam / Erasmus University, Sophia Children's Hospital, Department of Child and Adolescent Psychiatry, Rotterdam, The Netherlands

52. Verhulst FC, Van der Ende J, Koot HM (1997) Handleiding voor de Teacher's Report Form (TRF) [Manual for the TRF]. Department of Child and Adolescent Psychiatry, Sophia Children's Hospital, Erasmus University Rotterdam, Rotterdam

53. Wymbs BT, Pelham WE, Molina BSG, Gnagy EM, Wilson TK, Greenhouse JB (2008) Rate and predictors of divorce among parents of youths with ADHD. J Consult Clin Psychol 76:735744 